\title{
Cascading effects of a highly specialized beech-aphid- fungus interaction on forest regeneration
}

Specialist herbivores are thought to often enhance or maintain plant diversity within ecosystems, because they prevent their host species from becoming competitively dominant. In contrast, specialist herbivores are not generally expected to have negative impacts on non-hosts. However, we describe a cascade of indirect interactions whereby a specialist sooty mold (Scorias spongiosa) colonizes the honeydew from a specialist beech aphid (Grylloprociphilus imbricator), ultimately decreasing the survival of seedlings beneath American beech trees (Fagus grandifolia). A common garden experiment indicated that this mortality resulted from moldy honeydew impairing leaf function rather than from chemical or microbial changes to the soil. In addition, aphids consistently and repeatedly colonized the same large beech trees, suggesting that seedling-depauperate islands may form beneath these trees. Thus this highly specialized three-way beech-aphid-fungus interaction has the potential to negatively impact local forest regeneration via a cascade of indirect effects. 
1 Susan C. Cook-Patton: Smithsonian Environmental Research Center; cook-pattons@si.edu ${ }^{1}$

2 Lauren Maynard: Smithsonian Environmental Research Center; 1dmaynar@ncsu.edu

3 Nathan Lemoine: Florida International University; lemoine.nathan@gmail.com

4 Jessica Shue: Smithsonian Environmental Research Center; shuej@si.edu

5 John D. Parker: Smithsonian Environmental Research Center; parkerj@si.edu

$6 \quad{ }^{1}$ Corresponding author: cook-pattons@si.edu 
Introduction

9 Webb and Peart 1999; Carson and Root 2000; Petermann et al. 2008). While specialist enemies

10 (i.e., those that feed on one or a few closely related species) can in some cases remove entire

11 species from the plant community (e.g., Herms and McCullough 2014), they are generally

12 thought to have positive effects on plant biodiversity because they prevent any one species from

13 becoming competitively dominant (Janzen 1970; Connell 1971; Terborgh 2012). Similarly, when

14 specialist enemies are lost, which can occur when a plant occupies a new range, that plant species

may become invasive and outcompete native biodiversity (Mack et al. 2000; Keane and Crawley 2002). In contrast, it is not generally expected that specialist enemies will negatively impact the growth and survival of non-host plant species. However, ecological systems often consist of complex interaction webs, and species may impact ecologically distant species indirectly via changes in either the densities or the traits of intermediary species (Abrams 1995). Thus, it is theoretically possible for specialist enemies to have cascading negative effects on the broader biotic community.

Here, we document the negative effects of a highly specialized three-way plant-herbivorefungal interaction on non-host plant species. Specifically, we examined the effect of wooly beech aphid (Grylloprociphilus imbricator (Fitch)) colonization on forest seedling communities. Wooly beech aphids (Fig. 1a) are common consumers of American beech trees (Fagus grandifolia) in eastern North American forests (Hottes and Frison 1931; Smith 1974; Blackman and Eastop 1994; Aoki et al. 2001). Known colloquially as "boogie-woogie aphids" for their tendency to shake their abdomen when disturbed, these aphids are frequently discussed in environmental blogs and state extension publications (e.g., Childs 2011; Virginia Department of Forestry 2013). However, their natural history is only barely described, and their ecology and impacts on cooccurring species is to our knowledge entirely uncharacterized. 
These wooly, white aphids form highly conspicuous colonies (Fig. 1b) on branches of

33 beech trees. The colonies can be up to 1.5 meters in length and contain thousands of individuals

34 (Hottes and Frison 1931; Smith 1974; Blackman and Eastop 1994; Aoki et al. 2001). A single,

35 wingless mother (or "fundatrix") starts a colony after hatching from an over-wintering egg (Smith

36 and Denmark 1984) and in North Carolina, this fundatrix and her parthenogenic offspring can be

37 found from April until November on beech trees (Smith and Denmark 1984). A second

38 generation of winged females ("sexuparae") may appear anytime between June and the end of

39 November (Smith and Denmark 1984; Aoki et al. 2001). In Maryland where we conducted our

40 research the aphid colonies may appear as early as May, but do not become common until late

41 August/early September (pers. obs.).

42 The aphid colonies are made more obvious by the fungal masses that form below them

43 (Fig. 1c). This fungus (Scorias spongiosa (Schwein.) Fr.) specializes on the aphid's sugar-rich

44 excrement or "honeydew" (Hughes 1976). S. spongiosa is found primarily in association with

45 Fagus species (Reynolds 1978), but also on Alnus species (Chomnunti et al. 2011). Initially the

46 fungus forms a brown, spongy mass that eventually turns black, hardens, and persists through

47 much of the winter. The fungus also coats the leaves of seedlings directly beneath the aphid

48 colonies (Fig. 1d).

49 We explored the factors determining aphid distributions across the forest landscape at

50 multiple spatial scales, as well as the consequences of aphids for the forest seedling community,

51 by combining two years of field observations in a mapped 16-ha forest with a common garden

52 experiment. We tested three principal hypotheses: [1] the distribution of aphids across the

53 landscape will be non-random, [2] the beech-aphid-sooty mold interaction will have negative

54 effects on seedling communities and [3] this negative effect will result from changes in soil

55 quality. Based on our initial observations, we predicted that aphids would be most common on

56 small trees in sunny patches and theories of negative density dependence suggested that specialist 
57 herbivores would also be more common in locations with high beech density (Janzen 1970;

58 Connell 1971). We predicted that seedlings beneath heavily infested branches would have

59 increased mortality, based on our initial observations of seedling die-off in the forest, and that

60 aphid honeydew was reducing seedling survival because the carbon-rich inputs diminished soil

61 fertility (Stadler et al. 1998; Blumenthal et al. 2003).

\section{Methods}

Experimental site: All field surveys and soil collections occurred in the Smithsonian 31.2464"). In this 16-ha plot, which is further divided into $10010 \mathrm{~m} \times 10 \mathrm{~m}$ subplots, the diameter and spatial location of all woody species $>1.0 \mathrm{~cm}$ dbh are known. We censused every beech $(\mathrm{N}=$ 659 trees) occurring within $12-13$ evenly spaced subplots per hectare (Fig. $2 \mathrm{a} ; \mathrm{N}=204$ ). For a random subset of the subplots ( $\mathrm{N}=258, \mathrm{~N}=129$ per year), we also collected light availability and soil moisture data. We gathered light data in August 2011 using an AccuPAR LP-80 ceptometer to record photosynthetically available light in the center of each plot, taking all measurements between $11 \mathrm{am}$ and $4 \mathrm{pm}$ on a mostly cloudless day. We then collected ambient light measurements from a nearby, unshaded area and calculated 'light transmittance' as the fraction of light in each forested location relative to ambient light. We collected soil moisture data in June 2011 using a Fieldscout TDR 300, with two soil moisture measurements taken from the southwest corner of each $10 \mathrm{~m} \times 10 \mathrm{~m}$ subplot.

772013 , we recorded aphid infestation by visually scanning beech trees from the base up to $\sim 20 \mathrm{~m}$.

78 Most colonies occurred within the first $10 \mathrm{~m}$ (pers. obs.), but it is possible that additional, unseen

79 colonies occurred much higher in the canopy. Aphids packed densely along a single branch or a 80 cluster of branches. We therefore scored infestations with an ordinal scale: $0=$ no aphids, $1=$ 
81 presence of aphids, $2=$ greater than $30 \mathrm{~cm}$ of branch covered, and $3=$ greater than $100 \mathrm{~cm}$

82 covered. In the second week of October 2012, we also selected 19 focal beech trees that occurred

83 within the northwest hectare of the SERC Forest Dynamics Plot. We chose trees that were 10-20

$84 \mathrm{~cm} \mathrm{dbh}$, because the trees of this size class were sufficiently large (only $7 \%$ of censused trees

85 were bigger), common, and varied in aphid infestation status. Six of the focal beech trees had no

86 aphids, seven had an aphid score of two, and six had an aphid score of three. We tagged and

87 identified every woody seedling within 1 -m of the focal tree $(\mathrm{N}=575$ total; 30 per adult on

88 average, ranging from 7 to 58), measured its initial height, and noted whether its leaves were

89 directly coated in sooty mold. In mid-June 2013, we returned to these seedlings to reassess height

90 and survival.

91 Common Garden Experiment: We collected the top $\sim 20 \mathrm{~cm}$ of soil in mid-May 2013 from

92 randomly selected, but similarly sized adult beech trees that occurred in the northwest corner of

93 the SERC Forest Dynamics Plot ( $\mathrm{N}=15$ adults with aphids in 2012, 15 adults without aphids).

94 For trees with aphids, we gathered soil from directly beneath the previous year's infestation

95 (within $0.5 \mathrm{~m}$ of the tree trunk). These areas were obvious because they had fewer seedlings,

96 blackened leaf litter, and black-encrusted branches directly above. For trees without aphids, we

97 gathered soil from an analogous position within $0.5 \mathrm{~m}$ of the tree trunk. We divided the soil from

98 each adult tree into six, sterilized tree tubes (Deepots, Recycled D40 cells; sterilized with 10\%

99 bleach, 10 minutes) and sterilized all tools between samples. Into each tube we planted a one-year

100 old seedling that naturally germinated in an adjacent, aphid-free forest patch. We employed six

101 different species (Acer rubrum, Carya alba, Fagus grandifolia, Liriodendron tulipifera, Platanus

102 occidentalis, and Quercus alba) and ensured that all species occurred once in each soil sample.

103 Seedlings grew suspended outdoors in elevated trays (Deepot N25T) and beneath two layers of

104 shade cloth, and were watered between May and August 2013. We measured initial seedling

105 height in May 2013, and in the third week of October 2013, we assessed height and survival. 
106

107

108

109

110

111

112

113

114

115

116

117

118

119

120

121

122

123

124

125

126

127

128

129

\section{Statistical Analyses}

Spatial Distribution. All analyses were conducted in R (v 3.0.2). To determine the local factors that influenced aphid infestation, we examined how the probability of aphid infestation depended on tree size (dbh), year (2012 vs. 2013), the number of beech trees within a subplot, light availability, and soil water content. For all analyses we used binomial logistic regression ( $g l m$ in R package stats, R Core Team). The first model included probability of infestation as a function of tree dbh and year, plus their interaction. The second model regressed probability of infestation against the number of beech trees in each subplot. In addition, we examined whether the severity of infestation in 2012 (aphid score of $0,1,2$, or 3) determined the probability of infestation in 2013. Finally, the third model included probability of infestation as a function of percent light transmittance and soil water content for subplots where environmental data were collected.

To examine the spatial scale at which aphid outbreaks occurred in both 2012 and 2013 , we calculated Moran's I for different distance classes. We first determined the proportion of infested trees in each subplot, and then utilized Euclidean distances between subplot centroids (Fortin and Dale 2005) to place subplots into 15 unique classes, ranging from 0 to 500 meters. For example, the first distance class consisted of all grids between 0 and 36 meters apart and the second distance class consisted of all grids between 37 and 71 meters apart. We then calculated Moran's $I$ for each distance class, using 999 random permutations of the data to determine the significance of the observed test statistic (Fortin and Dale 2005), and considered statistics falling outside of the $95 \%$ confidence interval as significant.

Forest seedling performance. We used generalized linear mixed effects models (glmer in R package lme4 (Bates et al. 2013)) to determine whether seedling growth and survival varied as a function of tree infestation status (aphid vs. no-aphid), treating survival as a binary response 
130 variable with a binomial distribution and growth as a continuous response variable with a normal

131 distribution. We constructed a second model to determine how survival and growth varied as a

132 function of honeydew coverage, where honeydew coverage was a three-factor predictor

133 (seedlings beneath uninfested trees, seedlings beneath infested trees but not directly covered in

134 sooty mold, and seedlings directly covered in sooty mold). For both models, we treated adult tree 135 as a random factor with seedling nested within adult.

136 Common Garden Experiment. Because the seedlings species could be grouped into early

137 successional species (Acer rubrum, Liriodendron tulipifera, and Platanus occidentalis) and late

138 successional species (Carya alba, Fagus grandifolia, and Quercus alba), we planned a priori

139 contrasts to determine whether the effects of soil treatment (aphid vs. no-aphids) differed

140 depending on successional status. We also used planned a priori contrasts to assess whether the

141 growth of beech seedlings differed from other species. We again analyzed seedling survival and

142 growth in the common garden experiment using generalized linear models, with soil treatment,

143 species successional category, and conspecific status (beech vs. not beech) as the predictors.

\section{Results}

145 Spatial distribution: Even though aphid infestations were significantly lower in 2013 than

146 in $2012(n=1288, z=8.26, p<0.001)$, patterns of colonization were consistent between years.

147 Aphids were more likely to infest trees that had hosted aphids in the previous year $(n=644, \mathrm{z}=$

$1488.26, p<0.001)$. Trees that had few to no aphids in 2012 had a very low probability of hosting

149 aphids in 2013. In contrast, trees with moderately sized aphid densities in 2012 (aphid score $=2$ )

150 had a significantly higher probability of being infested in $2013(0.301 \pm 0.050$, probability \pm SE;

$151 z=7.51, p<0.001$ ), and trees with severe infestations in 2012 had a very high probability of

152 being recolonized in $2013(0.889 \pm 0.074$, probability $\pm \mathrm{SE} ; z=7.07, p<0.001)$. 
154 observed large infestations (aphid score $=3$ ) on trees with dbh values ranging from 3.3 to 55.6

$155 \mathrm{~cm}$ in 2012, and 3.8 to $32.3 \mathrm{~cm}$ in 2013 . However, aphids were more common on larger beech

156 trees, with the probability of infestation increasing with dbh $(n=1288, p<0.0001)$. Aphids did

157 not appear to recruit to denser patches of beech trees, as the proportion of beech trees infected in 158 each subplot did not depend on the number of beech trees in that subplot $(n=262, t=7.20, p=$ 159 0.223). Infestation did depend on the number of infested neighbors, however, as can be seen by 160 significantly clustered Moran's I values at small spatial scales (Fig. 2b). Aphid infestation was unrelated to either light $(n=258, p=0.678)$ or soil moisture

162 content $(n=258, p=0.890)$. Aphids may be responding to other environmental variables, 163 however, because aphid infestations were spatially clumped at small distances $(0-36 \mathrm{~m})$. This 164 clustering disappeared at larger spatial scales, however, with the distribution of infestation 165 becoming random after our first distance class (Fig. 2b). Forest seedling performance: Aphid colonization had negative consequences for the seedling community. When aphids were present, we always observed the co-occurrence of $S$. spongiosa suggesting that the aphids either carry the fungus with them, or that the fungus is ubiquitous (but dormant) in the environment. In the absence of aphids and fungus, seedling survival was very high: $90 \% \pm 2.7 \%$ of the tagged seedlings survived between 2012 and 2013

171 (mean $\pm \mathrm{SE}$ ). In contrast, seedlings directly covered in honeydew/sooty mold had significantly 172 lower survival $\left(80 \pm 4.2 \%\right.$, mean $\pm \mathrm{SE} ; n=575, X^{2}=7.40, p=0.030$; Fig. 3$)$. This effect appears 173 to be fairly localized, as seedlings that occurred under infested trees but outside of the honeydrew 174 drip zone did not show diminished survival $(89 \pm 2.4 \%$, mean $\pm \mathrm{SE} ; z=0.51, p=0.611)$. Thus, 175 seedling survival did not depend on whether aphids occurred on the nearest adult tree, but instead 176 on whether they were covered with honeydew/sooty mold $(z=2.18, p=0.030 ;$ Fig. 3). Growth of 177 the surviving seedlings showed the same patterns as survival, but did not significantly differ 
178 among aphid $(n=470, F=0.48, p=0.493)$ or honeydew conditions $(n=470, F=0.57, p=$

179 0.571). Beech seedlings also did not have different growth or survival than other seedling species

180 ( $p>0.1$ for all tests), suggesting that they experienced little to no negative feedback from adult

181 beech trees in the field.

182 Common garden experiment: The effect of aphids on seedling survival and growth does

183 not appear to be mediated through changing soil conditions, because seedling survival was the

184 same in soil from beneath infested and uninfested beech trees $(n=178$, survival: $z=0.22, p=$

185 0.603; growth: $t=-0.38, \mathrm{p}=0.665)$. Otherwise, patterns of growth were consistent with other

186 ecological predictions that early successional species would have higher growth rates than late

187 successional species $(t=-5.99, p=0.001)$, and that conspecific beech seedlings would have

188 reduced growth compared to other species (with significantly lower growth than Acer rubrum $(t=$

189 6.73, $p<0.001)$ and $P$. occidentalis $(t=4.37, p<0.001))$.

\section{Discussion}

191

Although wooly beech aphids are a common herbivore on American Beech trees in

192 eastern North America, their ecology is almost entirely unknown. Here, we show that a three-way

193 interaction among a specialist aphid, its host tree, and a fungal specialist on honeydew negatively

194 impacts forest regeneration. We observed that tree seedlings, regardless of species identity,

195 suffered elevated mortality when they were positioned directly under aphid colonies. However, in

196 a common garden experiment seedlings grown in soil from infested and uninfested trees

197 performed similarly, indicating that seedling mortality beneath aphid colonies resulted not from

198 changes in soil quality, but from the sooty mold impairing leaf function. The aphids also

199 preferentially and repeatedly colonized the same large beech trees, suggesting that negative

200 effects of this highly specialized aphid-beech-fungal interaction are creating islands of seedling-

201 depauperate patches. 
There are two avenues by which the beech-aphid-fungal interaction could impact

203

204

205

206

207

208

209

210

211

212

213

214

215

216

217

218

219

220

221

222

223

224

225

226

seedling mortality: changes in soil quality and/or impairment of leaf function. Aphid honeydew represents a carbon rich input into the soil, which would alter $\mathrm{C}: \mathrm{N}$ ratios and diminish soil fertility (Stadler et al. 1998; Blumenthal et al. 2003). We thus initially hypothesized that reductions in seedling performance would be due to changes in soil quality. However, when we grew seedlings from six different tree species in soil collected from directly beneath aphid colonies and from equivalent areas beneath uninfested trees, we observed no differences in seedling growth or survival. Thus, if honeydew was altering soil C:N ratios, the differences in soil nutrients were insufficient to affect seedling performance. Additionally, we only observed reduced seedling survival in the field when seedlings were directly covered in sooty mold, and not in nearby seedlings that fell outside of the honeydew drip line (Fig. 3). This highly localized effect implicates the honeydew and fungus as agents of mortality. Because the fungus is not known to infect leaf tissue (Hughes 1976), we believe that mortality resulted from diminished photosynthesis or impaired gas exchange rather than direct fungal infection.

At large spatial scales, we observed that the aphid colonies were distributed widely and randomly throughout a 16-ha forest plot (Fig. 2), counter to our hypothesis that aphids would be distributed non-randomly. However, at small spatial scales (less than $36 \mathrm{~m}$ ), aphid colonies were significantly clustered. Trees that were infested the previous year and/or close to other infested beech trees were more likely to be colonized. Very little is known about the dispersal and colonization patterns of wooly beech aphids. The second generation of wooly beech aphids, consisting entirely of winged females, are believed to migrate in late fall/early winter to their secondary host, the bald cypress, Taxodium distichum (L.) (Smith and Denmark 1984; Aoki et al. 2001). However, bald cypress is almost non-existent in the study area. The natural northern limit of bald cypress occurs at a site $\sim 50 \mathrm{~km}$ south of the study area at Battle Creek Cypress Swamp (Nature Conservancy 2014), although there is also a small patch of planted bald cypress on 
227 SERC property. Aphid species are known to disperse over long distances, especially if they move 228 up into the air stream (Compton 2002), but the repeated colonization of trees and clustering at 229 small spatial scales suggest that the aphids are overwintering locally, either on their primary host 230 trees or on an unknown secondary host.

231 The reappearance of aphid colonies on the same tree in subsequent years may be due to 232 limitations in wooly beech aphid dispersal or may be shaped by aphid choice for specific trees.

233 While our preliminary observations suggested that aphids were recruiting to sunny patches, the 234 systematic survey showed no effect of light availability on aphid colonization. Elevated light 235 conditions might increase host photosynthesis and potentially host quality, but it would not 236 directly increase phloem nitrogen content, and nitrogen is believed to limit most herbivorous 237 insects (Mattson 1980). Instead, we observed that the probability of aphid infestation increased 238 with beech size. A larger tree might recruit an aphid colony, because it is easier to locate in the 239 forest matrix or because it represents a better food source. We speculate that the former 240 mechanism is more likely. Wooly beech aphid colonies stem from a single fundatrix, so colony 241 size can serve as a proxy for host quality and we observed large aphid colonies (aphid score $=3$ )

242 on even very small saplings. Thus, small trees must provide sufficient nutrients to support a large 243 colony.

244 More generally, this paper provides an intriguing example of how a common, but poorly 245 characterized suite of specialists can have strong negative effects on non-host plant species via a 246 cascade of indirect effects. Because the negative effects of the fungus were indiscriminate with 247 regards to species and had an overall dampening effect on seedling diversity, this example runs 248 counter to the general ecological principal that specialist herbivores positively affect the broader 249 plant community by preferentially suppressing their host species (Connell 1971; Webb and Peart 250 1999; Keane and Crawley 2002; Terborgh 2012) 
252 Acknowledgements: We thank S McMahon, M LaForgia, K Edson and J Miguel for assistance

253 in the field, G Parker and two anonymous reviewers for insightful critique, and G Parker for

254 permission to use spatial and dbh data from the SERC Forest Dynamics Plot.

\section{References}

256 Abrams, P. A. 1995. Implications of dynamically variable traits for identifying, classifying, and 257 measuring direct and indirect effects in ecological communities. The American Naturalist $258 \quad 146: 112-134$.

259 Aoki, S., U. Kurosu, and C. D. von Dohlen. 2001. Colony defense by wingpadded nymphs in

260 Grylloprociphilus imbricator (Hemiptera: Aphididae). The Florida Entomologist 84:431-434.

261 Bates, D., M. Maechler, and B. M. Bolker. 2013. Linear mixed-effects models using S4 classes. R $262 \quad 3.0 .0$.

263 Blackman, R. L., and V. F. Eastop. 1994. Aphids on the World's Trees: An Identification and 264 Information Guide. CAB International, Wallingford.

265 Blumenthal, D. M., N. R. Jordan, and M. P. Russell. 2003. Soil carbon addition controls weeds 266 and facilitates prairie restoration. Ecological Applications 13:605-615.

267 Carson, W. P., and R. B. Root. 2000. Herbivory and plant species coexistence: community 268 regulation by an outbreaking phytophagous insect. Ecological Monographs 70:73-99.

269 Childs, R. 2011. Beech Blight Aphid. extension.umass.edu/landscape/fact-sheets/beech-blight270 aphid.

271 Chomnunti, P., C. L. Schoch, B. Aguirre-Hudson, T. W. Ko-Ko, S. Hongsanan, E. B. G. Jones, R. 272 Kodsueb, et al. 2011. Capnodiaceae. Fungal Diversity 51:103-134.

273 Compton, S. G. 2002. Sailing with the wind: dispersal by small flying insects. In J. M. Bullock, 274 R. E. Kenward, \& R. S. Hails, eds., Dispersal Ecology (1st ed., pp. 113-133). British 
276

277

278

279

280

281

282

283

284

285

286

287

Connell, J. H. 1971. On the role of natural enemies in preventing competitive exclusion in some marine animals and in rain forest trees. In P. J. den Boer \& G. R. Gradwell, eds., Dynamics of Populations (pp. 298-312). Center for Agricultural Publishing and Documentation, Wageningen, Netherlands.

Fortin, M.-J., and M. Dale. 2005. Spatial Analysis: A Guide for Ecologists. Cambridge University Press, Cambridge UK.

Herms, D. A., and D. G. McCullough. 2014. Emerald Ash Borer Invasion of North America: History, Biology, Ecology, Impacts, and Management. (M. R. Berenbaum, ed.) 59:13-30. Hottes, F. C., and T. H. Frison. 1931. The plant lice, or Aphididae, of Illinois. Bulletin of the Illinois Natural History Survey 19:123-447.

Hughes, S. J. 1976. Sooty Moulds. Mycologia 68:693-820.

Janzen, D. H. 1970. Herbivores and the number of tree species in tropical forests. The American Naturalist 104:501-528.

Keane, R., and M. Crawley. 2002. Exotic plant invasions and the enemy release hypothesis. Trends in Ecology and Evolution 17:164-170.

Mack, R., D. Simberloff, W. Lonsdale, H. Evans, M. Clout, and F. Bazzaz. 2000. Biotic invasions: Causes, epidemiology, global consequences, and control. Ecological Applications 10:689-710.

Mattson, W. J., Jr. 1980. Herbivory in relation to plant nitrogen content. Annual Review Of Ecology And Systematics 11:119-161.

Nature Conservancy, 2014. Battle Creek Cypress Swamp. Nature Conservancy.

Petermann, J. S., A. J. F. Fergus, L. A. Turnbull, and B. Schmid. 2008. Janzen-Connell effects are widespread and strong enough to maintain diversity in grasslands. Ecology 89:2399-2406.

Reynolds, D. R. 1978. Foliicolous ascomycetes 1: The capnodiaceous genus Scorias 
300 reproduction. Natural History Museum of Los Angeles County Contributions in Science 1-

$301 \quad 16$.

302 Smith, C. F. 1974. Keys to and descriptions of the genera of Pemphigini in North America

303 (Homoptera: Aphididae: Pemphiginae). Technical Bulletin (North Carolina Agricultural

$304 \quad$ Experiment Station 226:61.

305 Smith, C. F., and H. A. Denmark. 1984. Life history and synonymy of Grylloprociphilus

306 imbricator (Fitch) (Homoptera: Aphididae). The Florida Entomologist 67:430-434.

307 Stadler, B., B. Michalzik, and T. Müller. 1998. Linking aphid ecology with nutrient fluxes in a

$308 \quad$ coniferous forest. Ecology 79:1514-1525.

309 Terborgh, J. 2012. Enemies maintain hyperdiverse tropical forests. The American Naturalist

$310 \quad 179: 303-314$.

311 Virginia Department of Forestry. 2013. Forest Health Review (pp. 1-16). Virginia Department of 312 Forestry, Charlottesville, VA.

313 Webb, C., and D. R. Peart. 1999. Seedling density dependence promotes coexistence of Bornean 314 rain forest trees. Ecology 80:2006-2017. 


\section{Figure 1}

Wooly beech aphids and its fungal specialist

Fig. 1 [a] Wooly beech aphids aphids, [b] aphid colony covering a beech branch, [c] Scoria spongiosa before it turns black, and [d] blackened S. spongiosa on the leaves of a seedling beneath an infested beech tree.

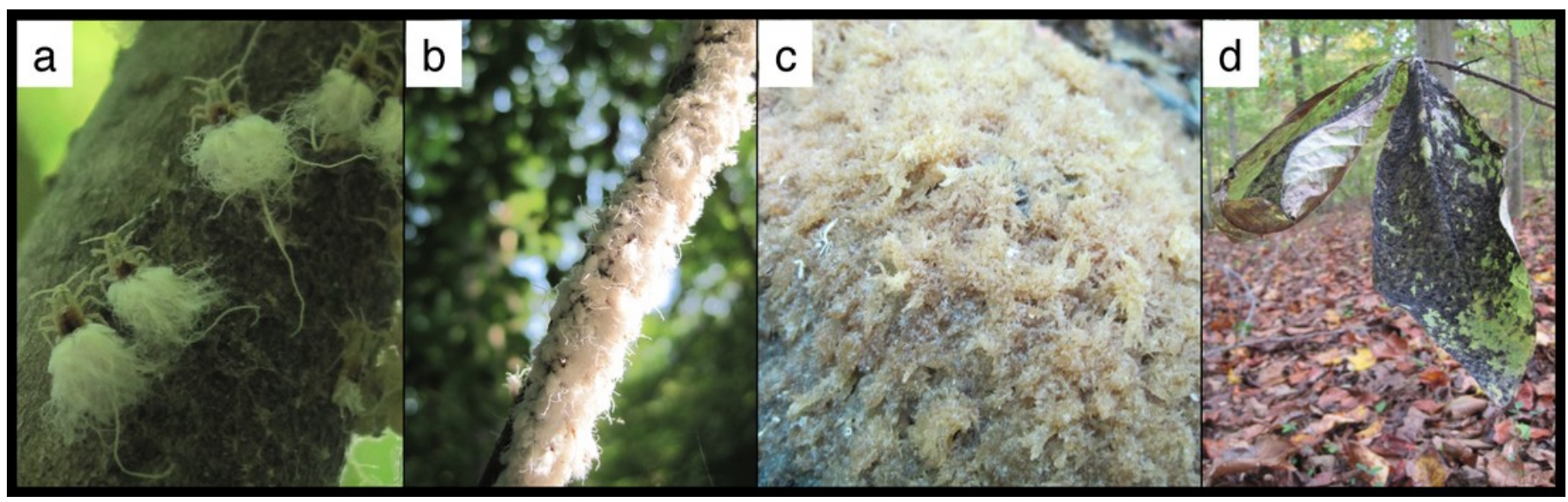




\section{Figure 2}

Spatial distribution of beech trees and aphids

Fig. 2 [a] Plot map with the number of beech trees in each subplot indicated by circle size and the number of aphid-infested trees indicated by color. Blank areas within the regular grid represent plots without beech trees, including the curved area from top right to bottom left where a stream occurs. [b] Spatial clustering at different spatial scales. The $\mathrm{x}$-axis represents the mean distance within a distance class. Points outside of the dashed confidence interval are significantly different than random, with points above showing significant clustering. 

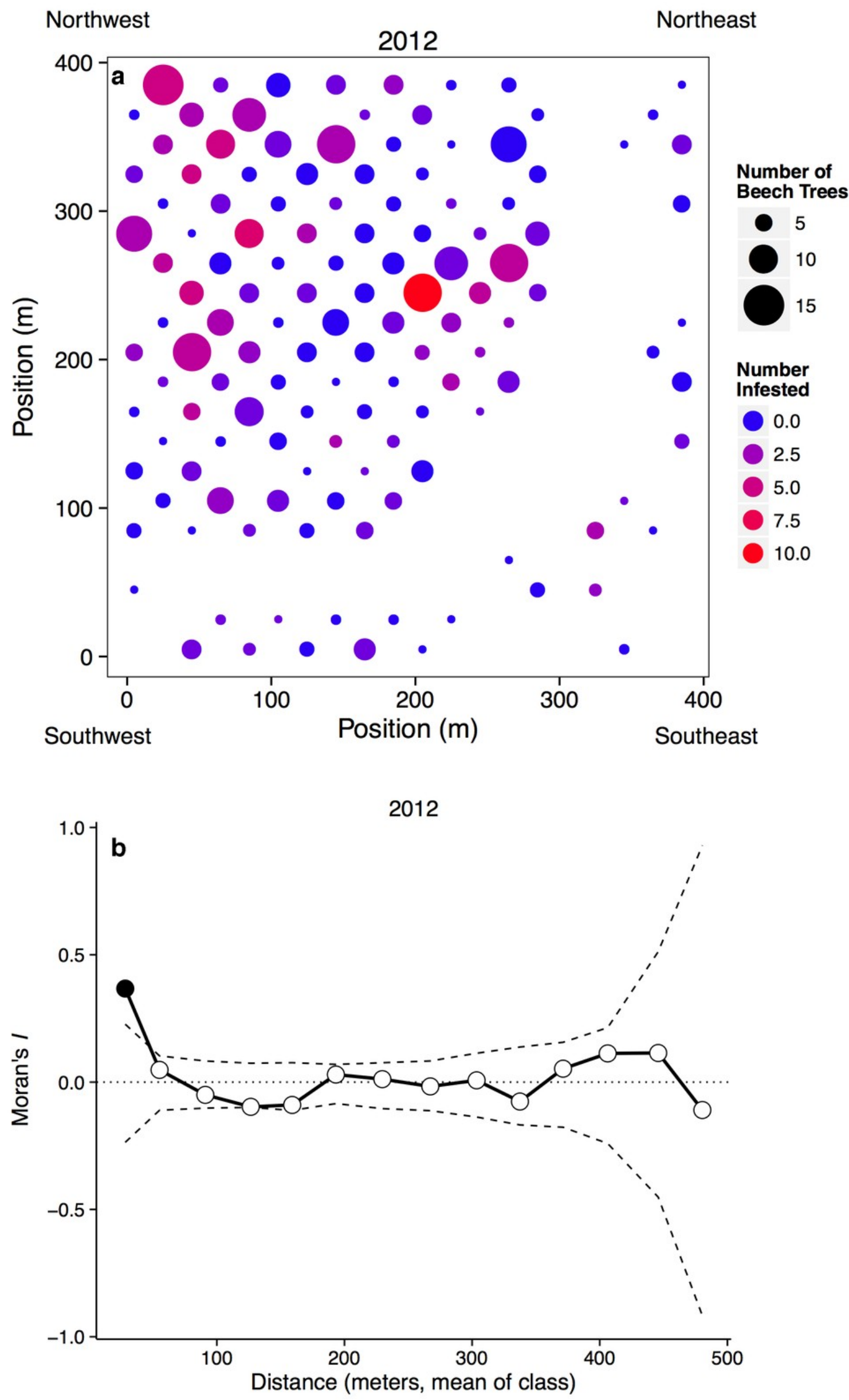


\section{Figure 3}

Forest seedling performance

Fig. 3 Probability of seedling survival beneath an uninfested tree, beneath an aphid-infested tree but not in the honeydew drip zone, or directly beneath a honeydew drip zone.

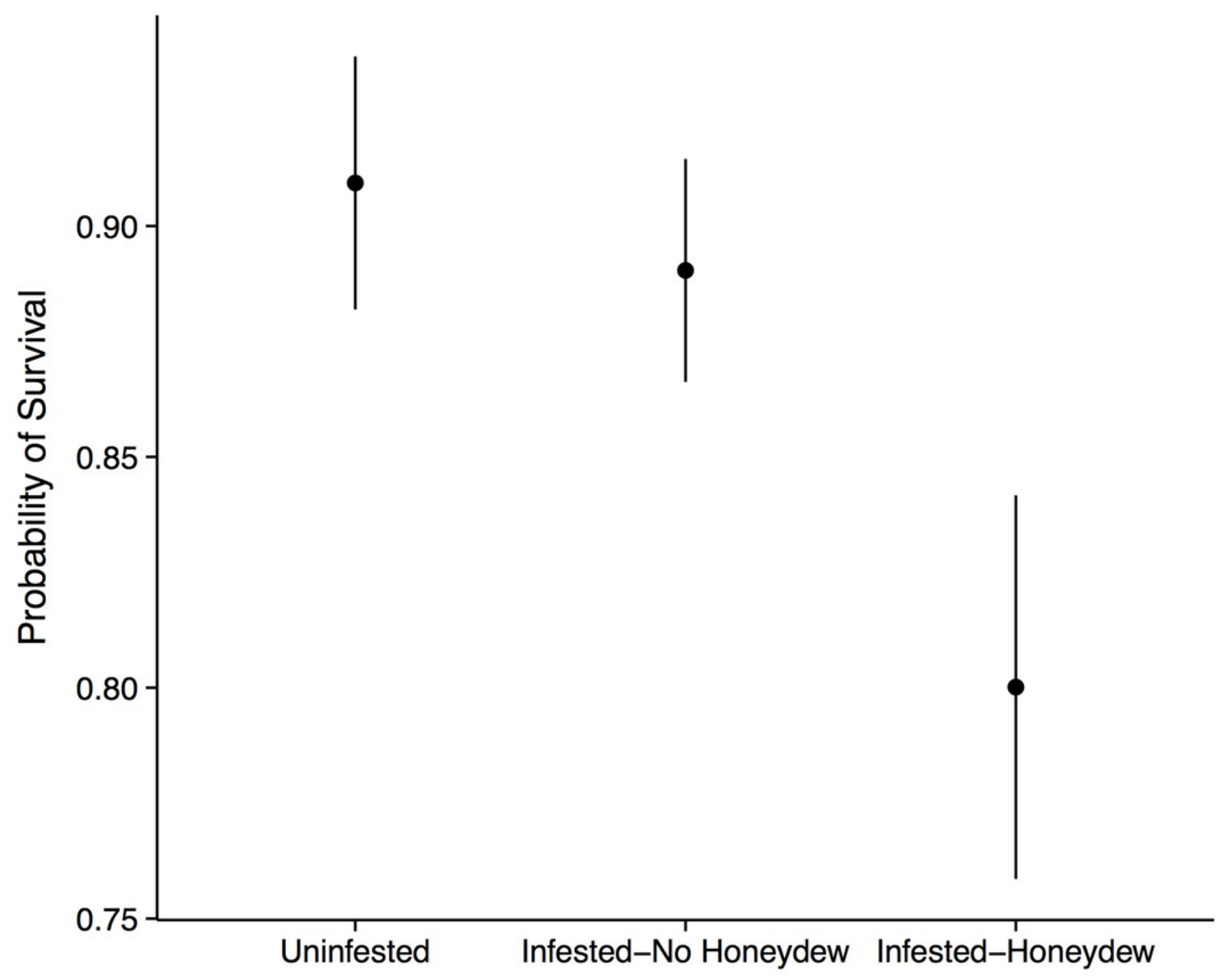

